\title{
Investigation of VSX1 sequence variants in South Indian patients with sporadic cases of keratoconus
}

\author{
Anshuman Verma', Manoranjan Das², Muthiah Srinivasan², Namperumalsamy V Prajna ${ }^{2}$ \\ and Periasamy Sundaresan ${ }^{1 *}$
}

\begin{abstract}
Background: The involvement of VSXI gene for the genetic basis of keratoconus is unclear and controversial. The genetic screening of VSX1 from different ethnic populations can enlighten this subject. The aim of the present study is to investigate the role of VSX1 gene in patients with sporadic cases of keratoconus from South India.

Methods: The VSX1 gene coding regions, including exon-intron boundaries were screened by direct sequencing analysis in 117 sporadic cases of keratoconus. The identified variations were also analyzed in 108 ethnic matched healthy blood donors.

Results: In the VSX1 gene screening, no pathogenic mutation was identified, whereas we could find the presence of four reported single nucleotide polymorphisms; c.546A $>G$ (rs12480307), c.627+23G>A (rs6138482), c.627+84T>A (rs56157240) and c.504-24C>T (IVS3-24C). These variations were observed in similar frequency between cases and controls.

Conclusions: The lack of VSX1 pathogenic variations in a large number of unrelated sporadic keratoconus patients tend to omit its role, and corroborate the involvement of other genetic, environmental or behavioural factors in the development of this complex disorder.
\end{abstract}

Keywords: KTCN - Keratoconus, VSX1 - Visual system homeobox 1, SNP - Single nucleotide polymorphism

\section{Background}

Keratoconus (KTCN; [OMIM] 148300) is a corneal ectatic disorder characterized by progressive thinning of the central cornea, which acquires a conical shape rather than its normal dome-shaped curve. This results in optical aberrations leading to distorted blurred vision, progressive high myopia and irregular astigmatism [1]. Keratoconus is mostly bilateral but can be unilateral, onset in teenage years and often progresses until the third or fourth decade of life [2]. The prevalence of keratoconus is estimated to be 1 in 2000 in the general population $[2,3]$. It is more common in patients with atopic conditions, such as asthma, dermatitis, and found to be associated with many other genetic disorders like Down syndrome, posterior polymorphous corneal dystrophy, Leber congenital amaurosis, retinitis

\footnotetext{
* Correspondence: sundar@aravind.org

'Department of Genetics, Dr. G. Venkataswamy Eye Research Institute, Aravind Medical Research Foundation, Aravind Eye Hospital, Madurai, Tamil Nadu, India Full list of author information is available at the end of the article
}

pigmentosa, Marfan syndrome, mitral valve prolapse and other documented associations $[1,2,4]$. It occurs usually in a sporadic form, though positive familial history has been reported in $6-10 \%$ of patients, with mostly autosomal dominant and sometime recessive or X-linked mode of inheritance [4-6]. Common histopathological features of KTCN include stromal thinning, iron deposition in the epithelial basement membrane, breaks in corneal Bowman's layer and sometimes endothelial damage $[2,7]$. The disease generally occurs with no gender preponderance; however, few evidence suggests a higher prevalence in either male or female $[1,6,8]$. At present, the milder forms of keratoconus are corrected by spectacles or contact lenses. In $10 \%$ to $20 \%$ of KTCN cases, corneal thinning may reach such a severity that it becomes very essential to undergo corneal transplantation or penetrating keratoplasty, which has emerged as a major medical burden in many countries [2,9]. The exact etiology of KTCN is still unknown, and its pathogenesis may involve genetic as well as environmental or 
behavioural factors, such as ultra-violet radiation UVB, atopy/allergy, contact lens wear and mechanical eye rubbing, etc. [10-12]. Primarily, the genetic factors may play an important role in the development of keratoconus as evidenced by studies of familial inheritance, concordance between monozygotic twins and association with other known genetic disorders [12-14]. By linkage analysis and association studies, various loci have been mapped in families from different ethnic populations, well summarized by Nowak DM et al. [12]. Based on associated loci, genes such as SPARC, $L O X$, TIMP3, COL6A1, COL8A1, MMP9, and MMP2, etc., have been examined for their involvement $[12,15]$. The $S O D 1$ and $C R B 1$ were also analyzed as possible candidate genes because of their role in keratoconus associated disease like Down syndrome and Leber congenital amaurosis respectively $[16,17]$. However, genes under such studies, have not provided enough evidence for being an appropriate candidate gene in the pathogenesis of KTCN. One of the well-studied genes in genetic association with keratoconus is VSX1. Human VSX1 [OMIM 605020] is a member of the VSX1 group of vertebrate paired-like homeodomain transcription factors localized to human chromosome 20p11-q11. Heon et al., [18] first identified VSX1 mutations in patients with either keratoconus or posterior polymorphous corneal dystrophy (PPCD). This led to the assumption that mutations in the VSX1 gene may be involved in pathogenesis of keratoconus. A number of other studies, further showed the presence of VSX1 variants in keratoconus patients from different ethnic populations [19-24]. Among them, several variants were found in highly conserved residues of $V S X 1$, and predicted to be pathogenic by the bioinformatics tools like PolyPhen, SIFT, etc. [21,23]. The exonic and intragenic polymorphisms were frequently reported in such studies, and found to be associated with the disease in a few cases $[22,25]$. On the other hand, many other studies excluded those previously reported $V S X 1$ variations to be pathogenic, and showed a lack of mutation or association [26-30]. Therefore, the role of VSX1 in KTCN pathogenesis is ambiguous, and further genetic studies are required for any persuasive conclusions. In this study, we have undertaken the sequence analysis of coding regions of VSX1 gene in order to determine its genetic involvement in South Indian patients with sporadic form of keratoconus.

\section{Methods}

\section{Clinical assessment}

Patients affected with keratoconus were recruited from cornea clinic, Aravind eye hospital, Madurai, between the period of 2009 to 2011 . The study consisted of 117 unrelated sporadic keratoconus patients, including 69 males and 48 females with an age range between 12 to
46 years old and mean age 23.1 years ( $\mathrm{SD} \pm 6.1$ years). A total of 108 ethnic-matched healthy blood donors with age range between 17 to 65 years old and mean age 24.6 years (SD \pm 9.4 ), including 27 males and 81 females, with no major ocular disorders were taken as controls. Any KTCN subjects with co-existing allergy/atopy, or systemic diseases/syndromes such as Down syndrome, Leber congenital amaurosis, Ehlers-Danlos syndrome, osteogenesis imperfecta and pellucid marginal degeneration, or post-LASIK or other refractive surgeries were excluded from this study. All study subjects belonged to South Indian ethnicity, mainly from the region of Tamil Nadu. Informed consent was obtained from each of the subjects. The study obeyed the tenets of the declaration of Helsinki and was approved by the institutional review board of Aravind eye hospital, Madurai, Tamil Nadu, India. The diagnosis of KTCN was based on the presence of important clinical features such as Munson's sign, Vogt's striae, Fleischer ring, prominent corneal nerves, corneal scarring, etc. The orbscan II parameters, (anterior float, posterior float, keratometry and pachymetry reading) operated with software version 3.12 (Bausch \& Lomb Inc., Rochester, NY) were taken for the final diagnosis using following measurements (a) ratio between the radius of anterior best-fit sphere (BFS) and posterior BFS $>1.27$ (b) power of posterior BFS $>55 \mathrm{D}$ (c) difference between highest and lowest posterior float points $>100 \mu$ (d) corneal thickness index (CTI) $>1.16$ (e) irregularity at $3 \mathrm{~mm}$ zone $>1.5 \mathrm{D} ; 5 \mathrm{~mm}$ zone $>2.5 \mathrm{D}$ and (f) $\mathrm{K}$ reading $>47 \mathrm{D}$. The patients diagnosed with forme-frusta keratoconus were not included in the study. Intra ocular pressure using pulsair non-contact tonometry was also taken for all patients. The study involved only sporadic keratoconus cases, and patients with a family history of KTCN were excluded. Furthermore, to confirm the sporadic nature of cases, three to four immediate available family members of each patient were clinically examined.

\section{DNA extraction and PCR amplification}

Genomic DNA was isolated from peripheral blood leukocytes using the salt precipitation method as described by Miller et al., [31]. The primer pairs used to amplify each of the five coding VSX1 exons were previously described [19]. PCR reaction (Eppendorf mastercycler, Westbury, NY) was carried out in a $20 \mu \mathrm{l}$ reaction mixture set up containing $2 \mu \mathrm{l}$ of $10 \mathrm{X}$ PCR buffer with 1.5 $\mathrm{mM} \mathrm{MgCl} 2,200 \mathrm{mM}$ dNTP, $0.2 \mathrm{mM}$ of each forward and reverse primer, 0.2 U Taq DNA polymerase (Sigma) and $50 \mathrm{ng}$ genomic DNA. The genomic DNA underwent initial denaturation for $5 \mathrm{~min}$ at $95^{\circ} \mathrm{C}$, followed by 35 cycles at $94^{\circ} \mathrm{C}$ for $1 \mathrm{~min}$, respective exons annealing at $58^{\circ} \mathrm{C}(\mathrm{ex} 1), 59^{\circ} \mathrm{C}(\mathrm{ex} 2), 62^{\circ} \mathrm{C}(\mathrm{ex} 3,4,5)$ for 1 min, extension at $72^{\circ} \mathrm{C}$ for $30 \mathrm{sec}$ and final extension for $5 \mathrm{~min}$ at 
$72^{\circ} \mathrm{C}$. The VSX1 gene coding regions with their exonintron junctions were examined by bidirectional sequencing analysis.

\section{DNA sequencing}

The PCR products were pooled and purified using the gel-elution kit method (Bio Basic Inc. Canada). The purified PCR products were sequenced bidirectionally using Big Dye Terminator ready reaction mix and analyzed on an ABI-3130 genetic analyzer (Applied Biosystems, Fostercity, CA). The sequence data analysis was done using BLAST software and compared with the published nucleotide sequence of the VSX1 gene [Gen Bank accession number NM_014588]. The identified variations were evaluated using Alamut software version 2.1e (Interactive Biosoftware, Rouen, France). The nomenclature, location and classification of variations were done based on the Alamut output.

\section{Comparative analysis}

A comparative statistical analysis of genotype and allele frequency was done using chi-square or Fisher's exact test in order to assess differences in the distribution of VSX1 polymorphism between cases and controls. The allelic p-value and odds ratio was determined for each of the identified $V S X 1$ variants.

\section{Results \& discussion}

A total of 117 sporadic KTCN patients were analyzed for coding and flanking intronic regions of VSX1 through bidirectional DNA sequencing analysis. In the VSX1 gene screening, no pathogenic mutations were identified whereas, four reported single nucleotide polymorphisms $\quad$ c.546A $>G$ (rs12480307), c.627+23G $>A$ (rs6138482), c.627+84T $>$ A (rs56157240) and c.50424C $>\mathrm{T}$ (IVS3-24C) could be observed (Table 1). Further, these four SNPs were investigated in 108 ethnic-matched healthy controls, and their genotype and allele frequency was compared between cases and control. The comparative statistical analysis of allele frequency of these SNPs indicated similar distribution in both patient and control groups (Table 2). The polymorphism c.546A>G (rs12480307) was found in exon 3 encoding a synonymous alanine substitution at 182 amino acid position, which is highly conserved throughout many species. This

Table 1 VSX1 sequence variants observed in the study

\begin{tabular}{ccccc}
\hline SNP ID & $\begin{array}{c}\text { VSX1 transcript } \\
\text { ID }\end{array}$ & $\begin{array}{c}\text { c.DNA } \\
\text { Change }\end{array}$ & $\begin{array}{c}\text { VSX1 } \\
\text { Protein ID }\end{array}$ & $\begin{array}{c}\text { Amino acid } \\
\text { change }\end{array}$ \\
\hline rs12480307 & NM_014588 & C.546A $>$ G & NP_055403 & p.A182A \\
rs6138482 & NM_014588 & c.627+23G>A & NP_055403 & $\ldots$ \\
rs56157240 & NM_014588 & c.627+84T>A & NP_055403 & $\ldots$ \\
(IVS3-24C) & NM_014588 & c.504-24C>T & NP_055403 & $\ldots$ \\
\hline
\end{tabular}

variation was seen in 43 cases (36 heterozygous and 7 homozygous) and 32 controls (28 heterozygous and 4 homozygous). The statistical analysis showed no significant difference of allelic distribution ( $\mathrm{p}$ value 0.205 ) among cases and controls. The polymorphic variant c.627+23G>A (rs6138482) was found in 29 cases (26 heterozygous and 3 homozygous) and 41 controls (40 heterozygous and 1 homozygous). The statistical analysis showed the allelic p value 0.099 , which was insignificant. The polymorphic variant c.627+84T >A (rs56157240) was found in 58 cases (49 heterozygous and 9 homozygous) and 50 controls (43 heterozygous and 7 homozygous) with no significant difference of allelic distribution between case and control groups ( $\mathrm{p}$ value 0.595). Another variant IVS3-24C>T (c.504-24C>T) was identified in 7 cases (7 heterozygous and 0 homozygous) and 7 controls (7 heterozygous and 0 homozygous) signifying its equal distribution (allelic pvalue 0.879 ) between cases and controls. This change was recently reported by Mukesh Tanwar et al., [25] as a novel VSX1 variant, and registered in GenBank [Accession number : GU471016].

\section{Conclusions}

In our study, we have assessed the role of $V S X 1$ by sequence analysis of its five exons in 117 sporadic KTCN patients. Our screening showed the absence of pathogenic variations whereas, four previously reported SNPs were observed. Since no pathogenic changes were detected, we compared the genotype and allele frequency of each of the identified polymorphisms between the disease cohort and healthy controls to access their possible disease involvement. However, allele frequencies of these identified SNPs were found in similar frequency between cases and controls confirming their non-pathogenicity. Other VSX1 gene variations such as p.D144E, p.L17P, p.N151S p.G160D, p.P247R, p.L159M, p.G160V, p.Q175H, p.R166W and p.H244R, reported in different previous $V S X 1$ studies were not identified in our analysis [18-22,24,29]. There are few earlier studies, which have indicated the association of non pathogenic VSX1 variations. Stabuc-Silih et al., [25] found an absence of VSX1 pathogenic mutations but observed an association of $c .650 \mathrm{G}>\mathrm{A}$ polymorphism $(\mathrm{p}=0.043)$ in unrelated Slovenian patients diagnosed with the hereditary form of KTCN. Mok et al., [20] found a significant association of one VSX1 intragenic polymorphism 'IVS1-11' in unrelated Korean keratoconus patients $(\mathrm{p}=0.001)$. Mutational screening of 66 unrelated patients with keratoconus (27 familial cases; 39 sporadic cases) from the European population, showed a minor role of VSX1 in the pathogenesis of keratoconus [22]. However, several other studies have shown the absence of pathogenic variations or lack of association of VSX1 variants with KTCN. Tang YG et al., [29] ruled out 
Table 2 Frequencies of VSX1 gene variants in sporadic KTCN cases and healthy controls

\begin{tabular}{|c|c|c|c|c|c|c|c|c|}
\hline \multicolumn{3}{|c|}{ VSX1 gene variations } & \multicolumn{2}{|c|}{ Case } & \multicolumn{2}{|c|}{ Control } & \multirow{2}{*}{$\begin{array}{l}\text { Allelic } \\
\text { p value }\end{array}$} & \multirow[t]{2}{*}{ OR $(95 \% \mathrm{Cl})$} \\
\hline & & & $n=117$ & $\%$ & $n=108$ & $\%$ & & \\
\hline \multirow[t]{5}{*}{$(r s 12480307)$ c.546A>G } & Genotype & AA & 74 & 63.2 & 76 & 70.4 & & \\
\hline & & GA & 36 & 30.8 & 28 & 25.9 & & \\
\hline & & GG & 7 & 6.0 & 4 & 3.7 & & \\
\hline & Allele & A & 184 & 78.6 & 180 & 83.4 & 0.205 & $0.74(0.44-1.21)$ \\
\hline & & G & 50 & 21.4 & 36 & 16.6 & & \\
\hline \multirow[t]{5}{*}{ (rs6138482) c.627+23G>A } & Genotype & GG & 88 & 75.2 & 67 & 62.0 & & \\
\hline & & GA & 26 & 22.2 & 40 & 37.0 & & \\
\hline & & AA & 3 & 2.6 & 1 & 0.9 & & \\
\hline & Allele & G & 202 & 86.3 & 174 & 80.6 & 0.099 & $0.66(0.38-1.12)$ \\
\hline & & A & 32 & 13.7 & 42 & 19.4 & & \\
\hline \multirow[t]{5}{*}{ (rs56157240) c.627+84T>A } & Genotype & $\pi$ & 59 & 50.4 & 58 & 53.7 & & \\
\hline & & TA & 49 & 41.9 & 43 & 39.8 & & \\
\hline & & AA & 9 & 7.7 & 7 & 6.5 & & \\
\hline & Allele & $\mathrm{T}$ & 167 & 71.4 & 159 & 73.6 & 0.595 & $1.12(0.72-1.73)$ \\
\hline & & A & 67 & 28.6 & 57 & 26.4 & & \\
\hline \multirow[t]{5}{*}{ IVS3-24C>T c.504-24C>T } & Genotype & CC & 110 & 94.0 & 101 & 93.5 & & \\
\hline & & $C T$ & 7 & $6 . .0$ & 7 & 6.5 & & \\
\hline & & $\pi$ & 0 & 0 & 0 & 0 & & \\
\hline & Allele & C & 227 & 97 & 209 & 96.7 & 0.879 & $1.09(0.32-3.69)$ \\
\hline & & $\mathrm{T}$ & 7 & 3 & 7 & 3.3 & & \\
\hline
\end{tabular}

OR-odds ratio, $\mathrm{Cl}$ - confidence interval, p-value less than 0.05 was considered as significant.

the association of previously reported VSX1 variations in a case-control study of 77 white KTCN patients. Liskova et al., [28], in a study of 85 familial keratoconus pedigrees from different ethnic origins, found a lack of pathogenic variations in VSX1 and disqualified the previously reported c.432C >G (p.D144E) change to be pathogenic. Aldave et al., [27] found the absence of mutation in 100 unrelated KTCN subjects and concluded that VSX1 mutations are not associated with keratoconus. Overall, our study also rules out the possible involvement of VSX1 gene in sporadic, South Indian KTCN patients. However, few previous evidence of VSX1 pathogenic variations and their association with disease, suggest that it is more likely to be involved in a smaller subset of the KTCN population. The role of VSX1 variations in a minority of keratoconus patients may be influenced by its possible variable penetrance or pleiotropic effect in corneal tissue.

Our study supports the previous evidence of lack of pathogenic variations in VSX1, and corroborates the involvement of new genes, loci or any other genetic or environmental factors. Linkage analysis and association study are the two main approaches used to identify novel genes. Genome wide association study (GWAS) is a more useful approach as it is wide-ranging, unbiased and can be applied even in the absence of convincing indication regarding the function or location of the causal genes. The other genetic factors are needed to be investigated for KTCN pathogenesis. Abu-Amero et al., [32], analyzed VSX1 chromosomal copy number variations (deletions/duplications) in a group of sporadic patients, who were excluded for VSX1 mutations, and verified that such possible genetic changes are also not involved in keratoconus. Recent studies find that keratoconus corneas have signs of oxidative stress and high level of mitochondrial DNA damage [33]. More recent findings suggest that micro-RNA can be involved in the pathogenesis of keratoconus [34]. Therefore, mitochondrial genes and micro-RNA are the prospective emerging areas to explore in the context of other genetic factors related to keratoconus. Proteomic profiles in the KTCN corneas and tear have shown differential expression of several proteins, which may have possible role in the etiology of keratoconus [35-37]. Hence, genetic and proteomic approaches together can provide more useful information regarding disease etiology. For the genetic basis of keratoconus, other genetic factors, new chromosomal loci and genes are the subject of investigation to accomplish the better understanding of the pathogenesis of disease. 


\section{Abbreviations}

KTCN: Keratoconus; VSX1: Visual system homeobox 1; PCR: Polymerase chain reaction; SNP: Single nucleotide polymorphism; DNA: Deoxyribonucleic acid LASIK: Laser-assisted in situ keratomileusis.

\section{Competing interests}

ALCON has provided the financial support for this project. AMRF has provided the partial support for article processing charge.

\section{Authors' contributions}

AV and PS carried out the molecular genetic studies, participated in the sequence analysis and drafted the manuscript. MD, MS and NVP equally participated in the recruitment and clinical diagnosis of patients, helped in the design and coordination of the study. All authors read and approved the final manuscript.

\section{Acknowledgments}

The authors would like to thank the patients and volunteers who participated in this study, Dr. Jaya Chidambaram for her valuable suggestions and Mrs. Mohana Priya for her technical assistance.

\section{Author details}

${ }^{1}$ Department of Genetics, Dr. G. Venkataswamy Eye Research Institute, Aravind Medical Research Foundation, Aravind Eye Hospital, Madurai, Tamil Nadu, India. ${ }^{2}$ Cornea Clinic, Aravind Eye Hospital, Madurai, Tamil Nadu, India.

Received: 19 September 2012 Accepted: 15 January 2013

Published: 18 March 2013

\section{References}

1. Ambekar R, Toussaint KC Jr, Wagoner JA: The effect of keratoconus on the structural, mechanical, and optical properties of the cornea. J Mech Behav Biomed Mater 2011, 4:223-236.

2. Rabinowitz YS: Keratoconus. Surv Ophthalmol 1998, 42:297-319.

3. Kennedy RH, Bourne WM, Dyer JA: A 48-year clinical and epidemiologic study of keratoconus. Am J Ophthalmol 1986, 101:267-273.

4. Rabinowitz YS: The genetics of keratoconus. Ophthalmol Clin North Am 2003, 16:607-620

5. Rabinowitz YS, Maumenee $\mathbb{H}$, Lundergan MK, Puffenberger E, Zhu D, Antonarakis $S$, et al: Molecular genetic analysis in autosomal dominant keratoconus. Cornea 1992, 11:302-308.

6. Abu-Amero KK, Kalantan H, Al-Muammar AM: Analysis of the VSX1 gene in keratoconus patients from Saudi Arabia. Mol Vis 2011, 17:667-672.

7. Sturbaum CW, Peiffer RL Jr: Pathology of corneal endothelium in keratoconus. Ophthalmologica 1993, 206:192-208.

8. Millodot M, Shneor E, Albou S, Atlani E, Gordon-Shaag A: Prevalence and associated factors of keratoconus in Jerusalem: a cross-sectional study. Ophthalmic Epidemiol 2011, 18:91-97.

9. Dobbins KR, Price FW Jr, Whitson WE: Trends in the indications for penetrating keratoplasty in the midwestern United States. Cornea 2000, 19:813-816.

10. Lindsay RG, Bruce AS, Gutteridge IF: Keratoconus associated with continual eye rubbing due to punctal agenesis. Cornea 2000, 19:567-569.

11. Georgiou T, Funnell CL, Cassels-Brown A, O'Conor R: Influence of ethnic origin on the incidence of keratoconus and associated atopic disease in Asians and white patients. Eye (Lond) 2004, 18:379-383.

12. Nowak DM, Gajecka M: The genetics of keratoconus. Middle East Afr J Ophthalmol 2011, 18:2-6.

13. Bechara SJ, Waring GO 3rd, Insler MS: Keratoconus in two pairs of identical twins. Cornea 1996, 15:90-93

14. Tuft SJ, Hassan H, George S, Frazer DG, Willoughby CE, Liskova P: Keratoconus in 18 pairs of twins. Acta Ophthalmol 2012, 90:e482-e486.

15. De Bonis P, Laborante A, Pizzicoli C, Stallone R, Barbano R, Longo C, et al: Mutational screening of VSX1, SPARC, SOD1, LOX, and TIMP3 in keratoconus. Mol Vis 2011, 17:2482-2494.

16. Udar N, Atilano SR, Brown DJ, Holguin B, Small K, Nesburn AB, et al: SOD1: a candidate gene for keratoconus. Invest Ophthalmol Vis Sci 2006, 47:3345-3351.

17. McMahon TT, Kim LS, Fishman GA, Stone EM, Zhao XC, Yee RW, et al: CRB gene mutations are associated with keratoconus in patients with leber congenital amaurosis. Invest Ophthalmol Vis Sci 2009, 50:3185-3187.
18. Héon E, Greenberg A, Kopp KK, Rootman D, Vincent AL, Billingsley $G$, et al: VSX1: a gene for posterior polymorphous dystrophy and keratoconus. Hum Mol Genet 2002, 1:1029-1036.

19. Bisceglia L, Ciaschetti M, De Bonis P, Campo PAP, Pizzicoli C, Scala C, et al: VSX1 mutational analysis in a series of Italian patients affected by keratoconus: detection of a novel mutation. Invest Ophthalmol Vis Sci 2005, 46:39-45.

20. Mok J-W, Baek S-J, Joo C-K: VSX1 gene variants are associated with keratoconus in unrelated Korean patients. J Hum Genet 2008, 53:842-849.

21. Paliwal P, Singh A, Tandon R, Titiyal JS, Sharma A: A novel VSX1 mutation identified in an individual with keratoconus in India. Mol Vis 2009, $15: 2475-2479$

22. Dash DP, George S, O'Prey D, Burns D, Nabili S, Donnelly U, et al: Mutational screening of VSX1 in keratoconus patients from the European population. Eye 2010, 24:1085-1092

23. Paliwal $P$, Tandon $R$, Dube $D$, Kaur $P$, Sharma A: Familial segregation of a VSX1 mutation adds a new dimension to its role in the causation of keratoconus. Mol Vis 2011, 17:481-485.

24. Eran P, Almogit A, David Z, Wolf HR, Hana G, Yaniv B, et al: The D144E substitution in the VSX1 gene: a non-pathogenic variant or a disease causing mutation? Ophthalmic Genet 2008, 29:53-59.

25. Stabuc-Silih M, Strazisar M, Hawlina M, Glavac D: Absence of pathogenic mutations in VSX1 and SOD1 genes in patients with keratoconus. Cornea. 2010, 29:172-176.

26. Stabuc-Silih M, Strazisar M, Ravnik-Glavac M, Hawlina M, Glavac D: Genetics and clinical characteristics of keratoconus. Acta Dermatovenerol Alp Panonica Adriat 2010, 19:3-10.

27. Aldave AJ, Yellore VS, Salem AK, Yoo GL, Rayner SA, Yang H, et al: No VSX gene mutations associated with keratoconus. Invest Ophthalmol Vis Sci 2006, 7:2820-2822

28. Liskova P, Ebenezer ND, Hysi PG, Gwilliam R, El-Ashry MF, Moodaley LC, et al: Molecular analysis of the VSX1 gene in familial keratoconus. Mol Vis 2007, 13:1887-1891.

29. Tang YG, Picornell Y, Su X, Li X, Yang H, Rabinowitz YS: Three VSX1 gene mutations, L159M, R166W, and H244R, are not associated with keratoconus. Cornea. 2008, 27:189-192.

30. Tanwar M, Kumar M, Nayak B, Pathak D, Sharma N, Titiyal JS, et al: VSX1 gene analysis in keratoconus. Mol Vis 2010, 16:2395-2401.

31. Miller SA, Dykes DD, Polesky HF: A simple salting out procedure for extracting DNA from human nucleated cells. Nucleic Acids Res 1988, 16:1215.

32. Abu-Amero KK, Hellani AM, Al Mansouri SM, Kalantan H, Al-Muammar AM: High-resolution analysis of DNA copy number alterations in patients with isolated sporadic keratoconus. Mol Vis 2011, 17:822-826.

33. Pathak D, Nayak B, Singh M, Sharma N, Tandon R, Sinha R, et al: Mitochondrial complex 1 gene analysis in keratoconus. Mol Vis 2011, 17:1514-1525

34. Hughes AE, Bradley DT, Campbell M, Lechner J, Dash DP, Simpson DA, et al: Mutation altering the miR-184 seed region causes familial keratoconus with cataract. Am J Hum Genet 2011, 11:628-633.

35. Lee J-E, Oum BS, Choi HY, Lee SU, Lee JS: Evaluation of differentially expressed genes identified in keratoconus. Mol Vis 2009, 15:2480-2487.

36. Lema I, Brea D, Rodríguez-González R, Díez-Feijoo E, Sobrino T: Proteomic analysis of the tear film in patients with keratoconus. Mol Vis 2010, 16:2055-2061

37. Pannebaker C, Chandler HL, Nichols JJ: Tear proteomics in keratoconus. Mol Vis 2010, 16:1949-1957.

doi:10.1186/1756-0500-6-103

Cite this article as: Verma et al:: Investigation of VSX1 sequence variants in South Indian patients with sporadic cases of keratoconus. BMC Research Notes 2013 6:103 